\title{
Study of the Spectral Interferences of Zirconium on Other Analytes in the Analysis of Nuclear Materials by CCD-based ICP-AES
}

\author{
V.C. Adya, Arijit Sengupta*, and S.V. Godbole \\ Bhabha Atomic Research Centre, Trombay, Mumbai, India
}

\section{INTRODUCTION}

Trace metallic impurity analysis is one of the prime steps of chemical quality control of nuclear fuels and associated materials (1-17). Due to the high neutron absorption cross-section of rare earth elements, they have stringent specification limits because the presence of other elements beyond the specification limits changes the metallurgical properties of fuel materials. To achieve the desired burn-up, optimum life span of the fuel in the reactor, and successful running of the reactor, it is required to have specific physical and chemical quality control and quality assurance measures for nuclear fuels and associated materials.

Zirconium is accepted worldwide as the cladding material used in the nuclear industry due to its low neutron absorption cross-section. In addition, U-Zr, U-Pu-Zr, Zr$\mathrm{Nb}$, and other binary and ternary alloy materials are also gaining importance in the nuclear industries (18-25). Thus, there is the need to develop a method for the determination of trace constituents in a $\mathrm{Zr}$ matrix. Due to its line-rich emission spectra, the presence of $\mathrm{Zr}$ even at trace levels can lead to an over-estimation of the analytes due to spectral interferences. For the determination of trace metallic constituents, either they have to be separated physically from the trace metals using the d.c. arc carrier distillation technique (1-6) or chemical separation followed by ICP-AES analysis of the raffinate (7-15).
*Corresponding author.

E-mail: arijita@barc.gov.in

\section{ABSTRACT}

The major problem of determining trace analytes in nuclear materials by inductively coupled plasma atomic emission spectrometry (ICP-AES) is the spectral interference of matrix elements such as $\mathrm{U}, \mathrm{Pu}, \mathrm{Zr}$, Th, etc., originating from their line-rich emission spectra. Chemical or physical separation of the major matrix followed by the determination of trace metallic impurities in the raffinate is a well-accepted protocol in the nuclear industries. However, separation involves handling of the materials which increases the chances of contamination.

In this study, the spectral interferences of zirconium on the different analytical lines of 13 analytes (B, Cd, Sm, Dy, Gd, Na, $\mathrm{Mg}, \mathrm{Cr}, \mathrm{Ca}, \mathrm{V}, \mathrm{Sn}, \mathrm{Pb}$, and $\mathrm{Ag}$ ) were evaluated to identify the interference-free lines of those elements in the presence of $\mathrm{a} \mathrm{Zr}$ matrix. A charged coupled detector (CCD) was used because it offers more flexibility in the choice of additional analytical lines. The sensitivity and the detection limits of the analytical channels of the elements in the presence of a zirconium matrix were calculated. An analytical method was also developed for the determination of zirconium by ICP-AES, including identification of suitable analytical lines (343.823nm, $257.139 \mathrm{~nm}$, and $272.262 \mathrm{~nm}$ ) and their analytical performance such as sensitivity and detection limits.
Because sample handling in d.c arc distillation is minimized, the chances of contamination are also reduced. However, the technique suffers from poor precision. Inductively coupled plasma atomic emission spectrometry (ICP-AES) analysis requires increased sample handling during chemical separation of the major matrix and thus the chances of contamination are increased. But the benefits of ICPAES are better detection limits, as well as precision, than with d.c. arc carrier distillation. For ICP-AES analysis, a suitable extractant and feed conditioning are required which results in a preferential extraction of the major matrix without loss of the analytes, even at trace levels. Therefore, a method needs to be developed where sample handling is minimum and the analytical performances of the method (precision, detection limits, linear dynamic range, sensitivity, etc.) are superior.

In our previous study, an attempt was made to understand the spectral interference of $U$ on other analytes using CCD-based ICP-AES (26-27). In the present study, the spectral interference of $\mathrm{Zr}$ was studied on 13 analytes (B, Cd, Sm, Dy, Gd, Na, Mg, Cr, Ca, V, $\mathrm{Sn}, \mathrm{Pb}$, and $\mathrm{Ag}$ ) using a charged coupled device (CCD)-based detector. This technology offers the option of choosing additional, interference-free analytical lines of the analytes. An analytical method was also developed for the determination of $\mathrm{Zr}$ which involves identification of the suitable analytical lines of $\mathrm{Zr}(339.198 \mathrm{~nm}, 343.823 \mathrm{~nm}$, $257.139 \mathrm{~nm}$, and $272.262 \mathrm{~nm}$ ) and examination of their analytical performance (detection limits, sensitivity, etc.). 


\section{EXPERIMENTAL}

\section{Instrumentation}

The analytical experiments were carried out using a computer-controlled, high resolution, simultaneous atomic emission spectrometer (Spectro Arcos, Germany) with ICP and D.C. arc as the excitation sources and a charged coupled device (CCD) as the detector. The instrumental specification and experimental parameters are summarized in Table I. The detector system, consisting of linear arrays of the CCD detectors (3648 pixels/array), is thermally stabilized and together with an optical system provides the ability to choose alternate analytical lines. Figure 1 is a cross-sectional view of the detector.

\section{Reagents and Standard Solutions}

The standard solutions for the rare earth and other common impurity elements were prepared from CertiPUR ${ }^{\circledR}$ ICP multi-standard solutions (E-Merck, Darmstadt, Germany) by proper dilution with $0.5 \mathrm{M}$ $\mathrm{HNO}_{3}$. Suprapur ${ }^{\circledR} \mathrm{HNO}_{3}$ (E-Merck, Darmstadt, Germany) and quartz double-distilled water were used for preparing $0.5 \mathrm{M} \mathrm{HNO}_{3}$.

ICP-AES has a very high linear dynamic range of 104-106 which may be sufficient for two-point calibration. But in the present case and to obtain more precise and accurate values, we did multi-point calibration curves for each element using their standard solutions. An amount of $0.5 \mathrm{M} \mathrm{HNO}_{3}$ was used as the standard blank for all elements. The other concentrations which were used to obtain calibration curves were $0.1 \mu \mathrm{g} / \mathrm{mL}, 0.5 \mu \mathrm{g} / \mathrm{mL}$, $1 \mu \mathrm{g} / \mathrm{mL}, 2 \mu \mathrm{g} / \mathrm{mL}, 5 \mu \mathrm{g} / \mathrm{mL}$, $10 \mu \mathrm{g} / \mathrm{mL}, 20 \mu \mathrm{g} / \mathrm{mL}, 50 \mu \mathrm{g} / \mathrm{mL}$, $100 \mu \mathrm{g} / \mathrm{mL}, 200 \mu \mathrm{g} / \mathrm{mL}, 500 \mu \mathrm{g} / \mathrm{mL}$, and $1000 \mu \mathrm{g} / \mathrm{mL}$ for all elements. With regard to detector calibration, it is always advisable to do proper peak search for all analytical lines
TABLE I Specifications and Operating Conditions of ICP-AES

\begin{tabular}{ll}
\hline \multicolumn{2}{l}{ Instrumental Specifications } \\
\hline Optical design & Paschen-Runge mounting, Circular design \\
Focal length & $750 \mathrm{~mm}$ \\
Grating & Holographic \\
Groove density & 1800 grooves/mm (1), 3600 grooves/mm (2) \\
Wavelength range & $130-800 \mathrm{~nm}$ \\
Entrance slit width & 15 microns \\
Resolution (FWHM) & $0.01 \mathrm{~nm}$ from $130-450 \mathrm{~nm}$ \\
& $0.02 \mathrm{~nm}$ from $450-800 \mathrm{~nm}$ \\
Thermal regulation & Controlled to $30 \pm 1^{\circ} \mathrm{C}$ \\
Frequency & $27.12 \mathrm{MHz}$ \\
Pump & Dual channel peristaltic pump \\
Detector & Linear arrays of CCD (3648 pixels/array) \\
Nebulizer & Concentric nebulizer with cyclonic spray \\
& chamber \\
ICP-torch & Demountable, radial viewing \\
\hline Operating Condition & \\
\hline Coolant flow & $16 \mathrm{~L} / \mathrm{min}$ \\
Auxiliary flow & $0.6 \mathrm{~L} / \mathrm{min}$ \\
Total time of measurement & $28 \mathrm{~s}$ \\
Pump speed & $30 \mathrm{rpm}$ \\
RF power output & $0.8-1.5 \mathrm{~kW}$ \\
Input power & $230 \mathrm{~V}$ AC \\
\hline
\end{tabular}

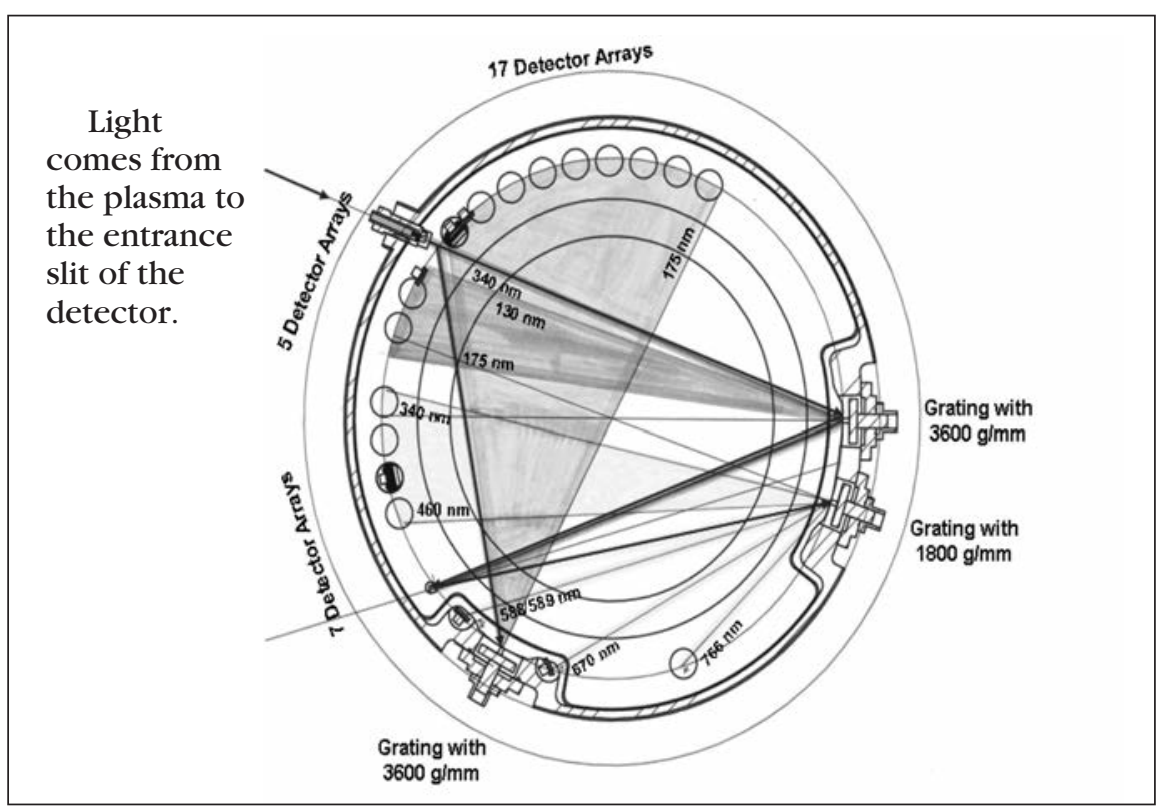

Fig. 1. Cross-sectional view of the array of pixels in CCD-based detector. 


\section{Atomic Spectroscopy \\ 1 Vol. 35(1), Jan./Feb. 2014}

used to get proper peak position, more counts, and appropriate calibration curves for each analytical line. This is generally done using $100 \mu \mathrm{g} / \mathrm{mL}$ of elemental standard. In the present case, this exercise was also carried out for all analytical lines of all the analytes.

To understand the spectral interference of $\mathrm{Zr}$ on other analytes, pure Zr solutions of different concentrations were used and the contributions at each analytical line were monitored.

\section{RESULTS AND DISCUSSION}

\section{Determination of Zirconium by ICP-AES}

Zirconium is a multi-electronic element having line-rich emission spectra. Due to the availability of high numbers of emission lines, the sensitivity of the lines were found to be less and the detection limits poorer with a photomultiplier tube (PMT)-based detection system. Exploring the superior analytical performance of the CCD-based detector system, an analytical method was developed for the determination of $\mathrm{Zr}$ by ICP-AES which included the identification of suitable analytical lines. Four emission lines of $\mathrm{Zr}$ were identified (339.198 nm, 343.823 nm, 257.139 $\mathrm{nm}$, and $272.262 \mathrm{~nm}$ ) and the calibration curves established. It was found that the $343.823 \mathrm{~nm}$, $257.139 \mathrm{~nm}$, and $272.262 \mathrm{~nm}$ lines can be used for the determination of $\mathrm{Zr}$ up to $1000 \mu \mathrm{g} / \mathrm{mL}$ with less than 5\% RSD, while for the 339.198 $\mathrm{nm}$ line, $200 \mu \mathrm{g} / \mathrm{mL}$ is the upper limit of detection for $\mathrm{Zr}$ (Table II). The sensitivity and detection limits of $\mathrm{Zr}$ with the above-mentioned analytical lines were evaluated using the slopes of the calibration curves and the concentration equivalent to the intensity equal to the average of the blank value plus three times the standard deviation of the above measurement (i.e., $x+3 \sigma)$. According to the analytical

TABLE II

Sensitivity of $\mathrm{Zr}$ by ICP-AES

\begin{tabular}{|c|c|c|c|c|}
\hline $\begin{array}{l}\text { Zr Conc. } \\
(\mathrm{mg} / \mathrm{L})\end{array}$ & $\begin{array}{c}\mathrm{Zr} \\
339.198 \mathrm{~nm} \\
\end{array}$ & $\begin{array}{c}\mathrm{Zr} \\
343.823 \mathrm{~nm} \\
\end{array}$ & $\begin{array}{c}\mathrm{Zr} \\
257.139 \mathrm{~nm} \\
\end{array}$ & $\begin{array}{c}\mathrm{Zr} \\
272.262 \mathrm{~nm} \\
\end{array}$ \\
\hline Blank & $\mathrm{BDL}^{*}$ & $\mathrm{BDL}^{*}$ & $\mathrm{BDL}^{*}$ & $\mathrm{BDL}^{*}$ \\
\hline 0.05 & 0.049 & 0.047 & 0.055 & 0.048 \\
\hline 0.10 & 0.102 & 0.104 & 0.113 & 0.104 \\
\hline 0.50 & 0.507 & 0.546 & 0.528 & 0.488 \\
\hline 1 & 1.03 & 1.05 & 1.08 & 1.03 \\
\hline 2 & 2.05 & 2.15 & 2.14 & 2.12 \\
\hline 5 & 5.04 & 5.47 & 5.25 & 5.06 \\
\hline 10 & 10.27 & 10.51 & 10.65 & 10.45 \\
\hline 20 & 20.62 & 21.52 & 21.32 & 21.349 \\
\hline 50 & 49.066 & 54.097 & 52.646 & 50.825 \\
\hline 100 & 97.716 & 102.065 & 106.519 & 102.998 \\
\hline 200 & 185.747 & 199.549 & 209.303 & 201.579 \\
\hline 500 & 337.206 & 471.176 & 482.468 & 474.171 \\
\hline 1000 & 339.024 & 845.756 & 952.495 & 919.305 \\
\hline $\begin{array}{l}\text { Det. Limit } \\
(\mu \mathrm{g} / \mathrm{mL})\end{array}$ & 0.02 & 0.09 & 0.341 & 0.1219 \\
\hline
\end{tabular}

${ }^{*} \mathrm{BDL}=$ Below Detection Limit.

performance, the emission line of $\mathrm{Zr}$ at $343.823 \mathrm{~nm}$ was found to be the best.

\section{Spectral Interference of $\mathrm{Zr}$ on the Analytes}

Interferences may originate from various transitions of the complex matrix system and spectral interference is the most significant in ICPAES analysis. Usually, for the determination of a particular analyte at trace levels, the most sensitive line is chosen. However, if the particular line is overlapped by some interfering line, another line needs to be selected which may be less sensitive and with poorer detection limits. Two analytical lines cannot be resolved in mainly two situations: (a) when the resolution of the instrument is poor and (b) when there is overlap between the two analytical channels which can never be separated regardless of the best resolution used in the instrument. In the first case, an instrument with better resolution can solve the problem while for the 2nd case the spectral interference needs to be studied and the correction factor evaluated, or otherwise one needs to choose alternative analytical lines for their determination. Improvement of the resolution of the instrument may resolve the lines only if the optics are responsible for the spectral overlap. If overlap of the lines is from a broadening process in the plasma, improvement of the instrumental resolution will be inefficient. Therefore, alternative emission lines need to be investigated for their analytical applicability. In some cases it may be that only the analytical line free from spectral interference has to be chosen. If this is the case, appropriate correction factors need to be evaluated.

Due to the advancement of the CCD detector (i.e., array of pixels) and the ability to choose an alternate analytical line, this lessens spectral interference. A detailed study was carried out to choose the 
appropriate emission line for the trace determination of 13 impurities in the presence of a $\mathrm{Zr}$ matrix.

Since B, Cd, the rare earth elements, and Ag have stringent specification limits, careful control of these constituents at each step of the fuel fabrication process is essential. Therefore, it is necessary to study the spectral interference of $\mathrm{Zr}$ on the analytical lines of these elements to avoid their overestimation which would be detrimental in qualifying the nuclear materials for the reactor.

Four analytical lines of B (249.773 nm, 249.677 nm, 182.641 $\mathrm{nm}$, and $208.959 \mathrm{~nm}$ ) were studied.
It was found that the spectral interference of $\mathrm{Zr}$ on these lines is negligibly small and all of the lines are suitable for the determination of $\mathrm{B}$. Though the Cd line at $361.051 \mathrm{~nm}$ showed strong spectral interference from $\mathrm{Zr}$, the three other analytical lines $(214.438 \mathrm{~nm}, 226.502 \mathrm{~nm}$, and $228.802 \mathrm{~nm}$ ) are relatively interference-free and also have lower detection limits. For the rare earth element samarium (Sm), the three lines at $359.260 \mathrm{~nm}, 428.079$ $\mathrm{nm}$, and $360.428 \mathrm{~nm}$ showed similar analytical performance, yet the first two lines had negligible interference from $\mathrm{Zr}$. Dysprosium (Dy) at $340.780 \mathrm{~nm}$ and gadolinium (Gd)

TABLE III

Contribution of $1000 \mu \mathrm{g} / \mathrm{mL}$ of $\mathrm{Zr}$ on Other Analytes

\begin{tabular}{|c|c|c|c|c|c|}
\hline Element & $\begin{array}{l}\text { Line } \\
(\mathrm{nm})\end{array}$ & $\begin{array}{c}\text { Contribution } \\
(\mu \mathrm{g} / \mathrm{mL})\end{array}$ & Element & $\begin{array}{l}\text { Line } \\
(\mathrm{nm})\end{array}$ & $\begin{array}{c}\text { Contribution } \\
(\mu \mathrm{g} / \mathrm{mL})\end{array}$ \\
\hline \multirow[t]{4}{*}{ B } & 249.773 & 0.032 & \multirow[t]{2}{*}{$\mathrm{Na}$} & 589.59 & 0.05 \\
\hline & 249.677 & 0.09 & & 588.99 & BDL \\
\hline & 182.641 & 0.04 & \multirow[t]{5}{*}{$\mathrm{Mg}$} & 279.55 & BDL \\
\hline & 208.959 & 0.03 & & 280.27 & BDL \\
\hline \multirow[t]{4}{*}{$\mathrm{Cd}$} & 214.438 & 0.018 & & 285.21 & 0.28 \\
\hline & 226.502 & 0.017 & & 279.07 & 0.6 \\
\hline & 228.802 & 0.021 & & 202.647 & 0.23 \\
\hline & 361.051 & 5.44 & \multirow[t]{6}{*}{$\mathrm{Ca}$} & 396.847 & 0.147 \\
\hline \multirow[t]{3}{*}{$\mathrm{Sm}$} & 359.26 & 0.083 & & 393.366 & 0.146 \\
\hline & 428.079 & 0.064 & & 317.933 & 0.2 \\
\hline & 360.428 & 0.2 & & 315.887 & 0.353 \\
\hline \multirow[t]{5}{*}{ Dy } & 353.17 & 0.026 & & 183.801 & 0.361 \\
\hline & 394.468 & 0.04 & & 422.673 & 0.22 \\
\hline & 340.78 & 1.376 & \multirow[t]{3}{*}{ V } & 292.464 & 7.5 \\
\hline & 353.602 & 0.354 & & 311.071 & 0.73 \\
\hline & 364.54 & 0.034 & & 292.402 & $\mathrm{BDL}$ \\
\hline \multirow[t]{4}{*}{ Gd } & 342.247 & 0.12 & \multirow{4}{*}{$\mathrm{Cr}$} & 309.311 & $\mathrm{BDL}$ \\
\hline & 335.047 & 1.07 & & 267.716 & 0.13 \\
\hline & 336.223 & 0.13 & & 205.618 & 0.15 \\
\hline & 335.862 & 0.19 & & 283.563 & 0.47 \\
\hline \multirow[t]{3}{*}{$\mathrm{Ag}$} & 328.068 & 20.98 & \multirow{5}{*}{ Sn } & 284.325 & 0.21 \\
\hline & 338.289 & 0.21 & & 284.984 & 0.29 \\
\hline & 338.202 & 0.06 & & 188.991 & 0.62 \\
\hline \multirow[t]{2}{*}{$\mathrm{Pb}$} & 220.353 & 0.19 & & 140.045 & 3 \\
\hline & 405.778 & 0.47 & & 242.949 & 0.31 \\
\hline
\end{tabular}

$\mathrm{BDL}=$ Below Detection Limit. 


\section{Atomic Spectroscopy \\ 1 Vol. 35(1), Jan./Feb. 2014}

TABLE IV

Determination of Sensitivity and Detection Limits of Different Analyte Emission Lines

\begin{tabular}{|c|c|c|c|c|c|c|c|}
\hline Element & $\begin{array}{l}\text { Wavelength } \\
\text { (nm) }\end{array}$ & $\begin{array}{l}\text { D.L. } \\
(\mu \mathrm{g} / \mathrm{mL})\end{array}$ & $\begin{array}{c}\text { Sensitivity } \\
\text { (Counts } / \mu \mathrm{g} / \mathrm{mL})\end{array}$ & Element & $\begin{array}{l}\text { Wavelength } \\
\text { (nm) }\end{array}$ & $\begin{array}{l}\text { D.L. } \\
(\mu \mathrm{g} / \mathrm{mL})\end{array}$ & $\begin{array}{c}\text { Sensitivity } \\
(\text { Counts } / \mu \mathrm{g} / \mathrm{mL})\end{array}$ \\
\hline \multirow[t]{3}{*}{$\mathrm{Ag}$} & 328.068 & 0.002 & $1.9 \times 10^{-5}$ & \multirow[t]{2}{*}{$\mathrm{Na}$} & 588.995 & 0.008 & $1.2 \times 10^{-5}$ \\
\hline & 338.289 & 0.003 & $4.1 \times 10^{-5}$ & & 589.592 & 0.002 & $2.2 \times 10^{-5}$ \\
\hline & 338.2 & 0.0004 & $1.2 \times 10^{-5}$ & \multirow[t]{2}{*}{$\mathrm{Pb}$} & 220.353 & 0.009 & 0.00015 \\
\hline \multirow[t]{4}{*}{ B } & 182.641 & 0.002 & $4.2 \times 10^{-5}$ & & 405.778 & 0.075 & 0.00046 \\
\hline & 208.959 & 0.0005 & $2.2 \times 10^{-5}$ & \multirow[t]{3}{*}{ V } & 292.402 & 0.0005 & $8.3 \times 10^{-6}$ \\
\hline & 249.677 & 0.002 & $3.3 \times 10^{-5}$ & & 292.464 & 0.001 & $1.2 \times 10^{-5}$ \\
\hline & 249.773 & 0.001 & $2.1 \times 10^{-5}$ & & 309.311 & 0.001 & $3.6 \times 10^{-6}$ \\
\hline \multirow[t]{5}{*}{ Dy } & 340.78 & 0.006 & $2.6 \times 10^{-5}$ & \multirow{4}{*}{$\mathrm{Sm}$} & 311.071 & 0.001 & $4.9 \times 10^{-6}$ \\
\hline & 353.17 & 0.001 & $4.5 \times 10^{-6}$ & & 359.26 & 0.003 & $2.4 \times 10^{-5}$ \\
\hline & 353.602 & 0.002 & $1.7 \times 10^{-5}$ & & 360.428 & 0.005 & $6.4 \times 10^{-5}$ \\
\hline & 364.54 & 0.002 & $1.4 \times 10^{-5}$ & & 428.079 & 0.007 & $3.9 \times 10^{-5}$ \\
\hline & 394.468 & 0.0009 & $1.7 \times 10^{-5}$ & \multirow[t]{3}{*}{ Sn } & 140.045 & 0.028 & 0.007 \\
\hline \multirow[t]{6}{*}{$\mathrm{Ca}$} & 183.801 & 0.005 & 0.00024 & & 189.991 & 0.004 & 0.00033 \\
\hline & 315.887 & 0.004 & $2.0 \times 10^{-5}$ & & 242.949 & 0.020 & 0.00018 \\
\hline & 317.933 & 0.003 & $9.9 \times 10^{-6}$ & \multirow[t]{4}{*}{ Gd } & 335.047 & 0.001 & $1.0 \times 10^{-5}$ \\
\hline & 393.366 & 0.0009 & $1.3 \times 10^{-7}$ & & 335.862 & 0.013 & $1.3 \times 10^{-5}$ \\
\hline & 396.847 & 0.0004 & $2.1 \times 10^{-7}$ & & 336.223 & 0.009 & $1.0 \times 10^{-5}$ \\
\hline & 422.673 & 0.002 & $1.7 \times 10^{-5}$ & & 342.247 & 0.001 & $1.5 \times 10^{-5}$ \\
\hline \multirow[t]{10}{*}{$\mathrm{Cd}$} & 214.438 & 0.0003 & $7.7 \times 10^{-6}$ & \multirow[t]{5}{*}{$\mathrm{Mg}$} & 202.647 & 0.006 & 0.00013 \\
\hline & 226.502 & 0.0008 & $8.1 \times 10^{-6}$ & & 279.079 & 0.011 & 0.00029 \\
\hline & 228.802 & 0.0006 & $8.1 \times 10^{-6}$ & & 279.553 & 0.001 & $5.3 \times 10^{-7}$ \\
\hline & 361.051 & 0.017 & 0.00042 & & 280.27 & 0.0005 & $9.1 \times 10^{-7}$ \\
\hline & & & & & 285.213 & 0.0002 & $4.6 \times 10^{-6}$ \\
\hline & & & & \multirow[t]{5}{*}{$\mathrm{Cr}$} & 205.618 & 0.016 & 0.0001 \\
\hline & & & & & 267.716 & 0.0005 & $2.7 \times 10^{-5}$ \\
\hline & & & & & 283.563 & 0.0013 & $1.1 \times 10^{-5}$ \\
\hline & & & & & 284.325 & 0.0027 & $1.5 \times 10^{-5}$ \\
\hline & & & & & 284.984 & 0.0013 & $2.3 \times 10^{-5}$ \\
\hline
\end{tabular}

D.L. = Detection Limit.

factor; (c) when spectral interference is moderate - the line can be used for analytical purposes but an appropriate correction factor should be incorporated. Table V summarizes the comparison of the spectral interference of $\mathrm{Zr}$ on different analytical lines of the elements mentioned earlier and their analytical performance. 
TABLE V (A)

Comparison of Types of Spectral Interference and Analytical Performance of Various Analytical Lines of the Analytes

\begin{tabular}{|c|c|c|c|}
\hline $\begin{array}{l}\text { Ele- } \\
\text { ments }\end{array}$ & $\begin{array}{l}\text { Analytical } \\
\text { Line } \\
(\mathrm{nm})\end{array}$ & Type of Spectral Interference & $\begin{array}{l}\text { Analytical Performance } \\
\text { (D.L. and Sensitivity) }\end{array}$ \\
\hline \multirow[t]{4}{*}{$\mathrm{B}$} & 249.773 & Negligible (correction factor not required) & Good and comparable with each other \\
\hline & 249.677 & Negligible (correction factor not required) & Good and comparable with each other \\
\hline & 182.641 & Negligible (correction factor not required) & Good and comparable with each other \\
\hline & 208.959 & Negligible (correction factor not required) & Best \\
\hline \multirow[t]{4}{*}{$\mathrm{Cd}$} & 214.438 & Negligible (correction factor not required) & Good and comparable with each other \\
\hline & 226.502 & Negligible (correction factor not required) & Good and comparable with each other \\
\hline & 228.802 & Negligible (correction factor not required) & Good and comparable with each other \\
\hline & 361.051 & Significant (shlould not use) & High D.L. \\
\hline \multirow[t]{3}{*}{$\mathrm{Sm}$} & 359.26 & Negligible(correction factor not required) & Good and comparable with each other \\
\hline & 428.079 & Negligible (correction factor not required) & Good and comparable with each other \\
\hline & 360.428 & Moderate (correction factor required) & Good and comparable with each other \\
\hline \multirow[t]{5}{*}{ Dy } & 353.17 & Negligible (correction factor not required) & Good and comparable with each other \\
\hline & 394.468 & Negligible (correction factor not required) & Good and comparable with each other \\
\hline & 364.54 & Negligible (correction factor not required) & Good and comparable with each other \\
\hline & 340.78 & Significant (should not use) & Good and comparable with each other \\
\hline & 353.602 & Moderate (correction factor required) & Good and comparable with each other \\
\hline \multirow[t]{4}{*}{ Gd } & 342.247 & Moderate (correction factor required) & Best comparable with 335.047 \\
\hline & 336.223 & Moderate (correction factor required) & Good and comparable with each other \\
\hline & 335.862 & Moderate (correction factor required) & Good and comparable with each other \\
\hline & 335.047 & Significant (should not use) & Best comparable with 342.247 \\
\hline \multirow[t]{3}{*}{$\mathrm{Ag}$} & 328.068 & Significant (should not use) & Good and comparable with each other \\
\hline & 338.289 & Moderate (correction factor required) & Good and comparable with each other \\
\hline & 338.202 & Negligible (correction factor not required) & Best \\
\hline \multirow[t]{2}{*}{$\mathrm{Pb}$} & 220.353 & Moderate (correction factor required) & Best \\
\hline & 405.778 & Moderate (correction factor required) & D.L. 10 times higher than the best line \\
\hline
\end{tabular}

D.L. $=$ detection limit 


\section{Atomic \\ $\bigcirc$ Vol. 35(1), Jan./Feb. 2014}

TABLE V (B)

Comparison of Types of Spectral Interference and Analytical Performance of Various Analytical Lines of the Analytes

\begin{tabular}{|c|c|c|c|}
\hline $\begin{array}{l}\text { Ele- } \\
\text { ments }\end{array}$ & $\begin{array}{l}\text { Analytical } \\
\text { Line } \\
\text { (nm) }\end{array}$ & Type of Spectral Interference & $\begin{array}{l}\text { Analytical Performance } \\
\text { (D.L. and Sensitivity) }\end{array}$ \\
\hline \multirow[t]{2}{*}{$\mathrm{Na}$} & 589.59 & Negligible (correction factor not required) & Best \\
\hline & 588.99 & Negligible (correction factor not required) & D.L. 4 times higher \\
\hline \multirow[t]{5}{*}{$\mathrm{Mg}$} & 279.55 & Negligible (correction factor not required) & Good \\
\hline & 280.27 & Negligible (correction factor not required) & Best \\
\hline & 285.21 & Moderate (correction factor required) & Best \\
\hline & 279.07 & Moderate (correction factor required) & Good \\
\hline & 202.647 & Moderate (correction factor required) & Good \\
\hline \multirow[t]{6}{*}{$\mathrm{Ca}$} & 396.847 & Moderate (correction factor required) & Best \\
\hline & 393.366 & Moderate (correction factor required) & Good comparable with each other \\
\hline & 317.933 & Moderate (correction factor required) & Good comparable with each other \\
\hline & 315.887 & Moderate (correction factor required) & Good comparable with each other \\
\hline & 183.801 & Moderate (correction factor required) & Good comparable with each other \\
\hline & 422.673 & Moderate (correction factor required) & Good comparable with each other \\
\hline \multirow[t]{4}{*}{$\mathrm{V}$} & 292.464 & Significant (should not use) & Good comparable with each other \\
\hline & 311.071 & Moderate (correction factor required) & Good comparable with each other \\
\hline & 292.402 & Negligible (correction factor not required) & Best \\
\hline & 309.311 & Negligible (correction factor not required) & Good comparable with each other \\
\hline \multirow[t]{5}{*}{$\mathrm{Cr}$} & 267.716 & Moderate (correction factor required) & Best \\
\hline & 205.618 & Moderate (correction factor required) & D.L. 20 times higher than the best line \\
\hline & 283.563 & Moderate (correction factor required) & Good comparable with each other \\
\hline & 284.325 & Moderate (correction factor required) & Good comparable with each other \\
\hline & 284.984 & Moderate (correction factor required) & Good comparable with each other \\
\hline \multirow[t]{3}{*}{ Sn } & 188.991 & Moderate (correction factor required) & Best \\
\hline & 140.045 & Moderate (correction factor required) & Good comparable with each other \\
\hline & 242.949 & Moderate (correction factor required) & Good comparable with each other \\
\hline
\end{tabular}

D.L. $=$ detection limit. 


\section{CONCLUSION}

A systematic study was carried out to understand the spectral interference of zirconium on 13 analytes (B, Cd, Sm, Dy, Gd, Na, Mg, Cr, Ca, $\mathrm{V}, \mathrm{Sn}, \mathrm{Pb}$, and $\mathrm{Ag}$ ) by CCD-based ICP-AES. The main advantage of using this technique is the arrays of the 3764 detector pixels which cover the entire wavelength range. This offers the choice of additional analytical lines of the elements free from spectral interference of an emission-rich matrix such as $\mathrm{Zr}$, U, $\mathrm{Pu}$, etc. With CCD-based ICP-AES, all analytes can be monitored simultaneously, and hence the sample requirement is less compared to the monochromator-based sequential ICP-AES spectrometer.

Interference-free analytical lines of these elements were identified, and the analytical performance (detection limits, sensitivity, etc.) of these lines were studied. An analytical method was developed for the determination of zirconium by ICPAES which includes identification of the suitable analytical lines, establishing the calibration curves, and evaluating the sensitivity and detection limits of Zr. It was observed that except for the $339.198 \mathrm{~nm}$ line (saturates beyond $200 \mu \mathrm{g} / \mathrm{mL}$ ), the other three analytical lines studied (343.823nm, $257.139 \mathrm{~nm}$, and $272.262 \mathrm{~nm}$ ) can be used for $\mathrm{Zr}$ determination resulting in $~ 5 \%$ RSD.

Received July 26, 2013

\section{REFERENCES}

1. T.G. Bangia, B.A. Dhawale, V.C. Adya, and M.D. Sastry, Fresenius J. Anal. Chem. 332, 802 (1988).

2. N.K. Porwal, A.A. Argekar, P.J. Pnrohit, A.G. Page, and M.D. Sastry, Fresenius J. Anal. Chem. 338, 255 (1990).

3. A. G. Page, K. H. Madraswala, S. V. Godbole, Madhuri J. Kulkarni, Vanita S. Mallapurkar, and B. D. Joshi, Fresenius Z Anal. Chem. 315, 38 (1983).

4. A.G. Page, S.V.Godbole, S. Deshkar, Y. Babu and B.D. Joshi, Fresenius J Anal. Chem. 287, 304 (1977).

5. A.G.I.Dalvi, C.S. Deodhar, T.K.Seshagiri, M.S.Khalap and B.D. Joshi, Talanta 25, 665 (1978).

6. T.G. Bangia, B.A. Dhawale, V.C. Adya, and M.D. Sastry, Fresenius J Anal. Chem. 332, 802 (1988)

7. K. Satyanarayana and S. Durani, J. Radioanal. and Nucl. Chem. 285 3), 659 (2010).

8. B. Rajeswari, B.A. Dhawale, T.R. Bangia, J.N. Mathur, and A.G. Page, J. Radioanal. and Nucl. Chem. 254 (3), 479 (2002).

9. A. Sengupta, M.J. Kulkarni and S.V. Godbole, J. Radioanal. Nucl. Chem., DOI 10.1007/s10967-0111222-8 (2011).

10. A.A. Argekar, M.J. Kulkarni, J.N. Mathur, and A.G. Page, Talanta 56, 591(2002).

11. C. Mahan, S. Bonchin, D. Figg, D. Gcrth, and C. Collier, J. Anal. At. Spectrom. 15(8), 929 (2000).

12. R.K. Malhotra and K. Satyanarayana, Talanta 50(3), 601 (1999).

13. S. Marin, S. Cornejo, C. Jara, and N. Duran, Fresenius' J. of Anal. Chem. 355(5-6), 680 (1996).

14. E.A. Huff, Spectrochim. Acta Part B: 42(1-2), 275 (1987)

15. E.A. Huff and D.L. Bowers, Appl. Spectrosc. 43(2), 223 (1989).

16. A.Sengupta, B.Rajeswari, R.M. Kadam and R. Acharya, At. Spectrosc. 32(5), 200 (2011).
17. A. Sengupta, V.C. Adya, Mithelesh Kumar, S.K. Thulasidas, S.V. Godbole and V.K. Manchanda, At. Spectrosc. 32(2), 49 (2011).

18. Arijit Sengupta, B. Rajeswari, R.M. Kadam and S.V. Godbole, At. Spectrosc. 33(2), 48 (2012)

19. O.J. Kond, K. Domen and I.J. Maruyak, Faraday Trans. 88, 2095 (1992).

20. R.M. Li, Z.S. Li and Y.F. Xin, Appl. Sci. Technol. 9, 52(2001).

21. N.E. Gordon, Jr., and R.M. Jacobs, Anal. Chem. 25, 1605 (1953).

22. C.L. Easterday, Anal. Chem. 31 (11), 1867 (1959).

23. I. Steffan and G. Vujicic, J. Anal. At. Spectrom. 9, 785 (1994).

24. X. Ma and Y. Li, Anal. Chim. Acta 579, 47 (2006).

25. M. Watanabe, A. Horiki and T. Uchidab, Anal. Chim. Acta 416, 117(2000).

26. Arijit Sengupta, V.C. Adya, T.K. Seshagiri and S.V. Godbole, At. Spectrosc. 34(2), 53 (2013).

27. Arijit Sengupta, V.C. Adya and S.V Godbole, J. Radioanal. Nucl. Chem., DOI 10.1007/s10967-0132520-0 (2013). 